\title{
Evaluation of an Expired Non-Toxic Amlodipine Besylatedrug as Corrosion Inhibitor for Low Carbon Steel in Hydrochloric Acid Solutions \\ A.S.Fouda, M.S.Motawee, H.E.Megahid, H.A.Abdul Mageed \\ Chemistry Dept., Faculty of Science, P.O.Box 35516, Benha Univ., Benha, Egypt \\ E-Mail: Asfouda@Mans.Edu.Eg
}

\begin{abstract}
Inhibition oflow carbon steel corrosion by Amlodipine Besylate in $1 \mathrm{M} \mathrm{HCl}$ was investigated by weight loss, potentiodynamic polarization, electrochemical impedance spectroscopy (EIS) and electrochemical frequency modulation (EFM) measurements. The inhibition efficiency (\%IE) increased with increase in inhibitor concentration but deceased with rise in temperature. The thermodynamic parameters of corrosion and adsorption processes were determined and discussed. The adsorption of these inhibitors was found to obey Langmuir adsorption isotherm. The results obtained from the three different techniques were in good agreement. Quantum structure-activity relationships have been used to study the effect of molecular structure on inhibition efficiency of the inhibitors. The surface morphology of carbon steel sample was investigated by scanning electron microscopy (SEM).
\end{abstract}

Keywords: Corrosion Inhibition; low carbon steel; $\mathrm{HCl}$; Amlodipine Besylate

\section{Introduction}

Corrosion is costly and severe materials science problem. The corrosion of low carbon steel is the most common form of corrosion, especially in acid solution. It has received a considerable attention as a result of its industrial importance, for example in the chemical cleaning and processing, oil well acidizing, petrochemical industry. Low carbon steel which is subjected to painting, electroplating, phosphatecoating, cold rolling, must have a clean surface free from oxide scale. To remove unwanted scale, the low carbon steel is immersed in an acid solution namely in an acid pickling bath. Hydrochloric acid solutions are by far the most widely used in pickling bath of low carbon steel. Because of the general aggressiveness of acid solutions, organic inhibitors are commonly used to reduce the corrosion attack on metallic materials.Majority of the well-known inhibitors for the corrosion of steel in acidic medium are organic compounds containing nitrogen, sulphur, oxygen atoms, or N-hetero cyclic compounds with polar groups. A large number of scientific studies have been devoted to the subject of corrosion inhibitors for low carbon steel in acidic media [1-12]. Most of the commercial inhibitors are toxic in nature; therefore, replacement by environmentally benign inhibitors is necessary.Few non-toxic compounds have been investigated as corrosion inhibitors by some researchers [13-16]. The use of pharmaceutical compounds offers interesting possibilities for corrosion inhibition due to the presence of hetero atoms like nitrogen, sulphurand oxygen in their structure, and they are of particular interest because of their safe use, high solubility in water and high molecular size. Some of the azosulpha and antimalarial drugs have been reported as good corrosion inhibitors [17-19]. Also, the use of piperazine [20], septazole [21] and Cefixime [22]drugsas corrosion inhibitors has been reported.

In the present work, expired Amlodipine Besylate drughas been investigated as corrosion inhibitor for low carbon steel in hydrochloric acid using different techniques. Amlodipine Besylate contains $\mathrm{N}$-atoms, $\mathrm{O}$-atoms and $\pi$-bond in its structure, regarded as important factors for good inhibitor performance.

\section{Materials and methods}

\subsection{Materials and solutions}

The working electrode was mechanically cut from cylindrical low carbon steel rod having composition (weight \%): C: 0.092; Mn: 0.239; Al: 0.037; Cr: 0.025; Si: 0.024; S: 0.020; $\mathrm{Cu}: 0.019$; Nb: 0.006; Sn: 0.005; As: 0.0038; V: 0.002; Co: 0.002; Ti: 0.002; B: 0.0014 and balance $\mathrm{Fe}$ ) of rectangular design having an area of $1 \mathrm{~cm}^{2}$ were used in this study. The surface of working electrode was abraded using different grades (320-1200 grade) of emery papers, degreased with acetone, washed with bidistilled water and dried with soft paper. The experimental measurements were carried out in $1 \mathrm{M} \mathrm{HCl}$ solution in the absence and presence of variousconcentrations of Amlodipine Besylate for all studies. The chemical structure of Amlodipine Besylate is given below. The concentrations of inhibitor employed were varied from 50 to $250 \mathrm{ppm}$. For each experiment, a freshly prepared solution was used.

\subsection{Weight loss tests}

Low carbon steel sheets of $20 \times 20 \times 2 \mathrm{~mm}$ were abraded with different grades of emery paper and then washed with bi-distilled water and acetone. After weighing accurately, the specimens were immersed in $100 \mathrm{ml} \mathrm{HCl}$ solution with and without addition of different concentrations of the drug. After $3 \mathrm{hrs}$, the specimens were taken out, washed, 
dried, and weighed accurately. The average weight loss of the three parallel low carbon steel sheets could be obtained at required temperature. The inhibition efficiency (IE) and the degree of surface coverage $(\theta)$ of the investigated drug on the corrosion of low carbon steel were calculated as follows [23]:

$$
\% \mathrm{IE}=\theta \times 100=\left[1-\left(\mathrm{W} / \mathrm{W}^{\circ}\right)\right] \times 100
$$

Where $\mathrm{W}^{\circ}$ and $\mathrm{W}$ are the values of the average weight loss without and with addition of the inhibitor, respectively<smiles>CCOC(=O)C1=C(COCCN)NC(C)=C(C(=O)OC)C1c1ccccc1Cl</smiles>

$(R S)$-3-ethyl 5-methyl 2-[(2 aminoethoxy) methyl]4-(2-chlorophenyl)-6-methyl-1,4-dihydropyridine-

3,5-dicarboxylate Molecular formula $\mathrm{C}_{20} \mathrm{H}_{25} \mathrm{Cl}$ $\mathrm{N}_{2} \mathrm{O}_{5}$, Molecular weight $=408.9$

\subsection{Electrochemical measurements 2.3.1 Potentiodynamic polarization measurements}

Polarization experiments were carried out in a conventional three-electrode cell with platinum gauze as the auxiliary electrode and a saturated calomel electrode (SCE) coupled to a fine Luggin capillary as reference electrode. The working electrode was in the form of a square cut from low carbon steel sheet of equal composition embedded in epoxy resin of polytetrafluoroethylene so that the flat surface area was $1 \mathrm{~cm}^{2}$. Prior to each measurement, the electrode surface was pretreated in the same manner as the weight loss experiments. Before measurements, the electrode was immersed in solution for $30 \mathrm{~min}$. until a steady state was reached. The potential was started from - 600 to + $400 \mathrm{mV}$ vs. open circuit potential $\left(\mathrm{E}_{\mathrm{ocp}}\right)$. All experiments were carried out in freshly prepared solutions at $30^{\circ} \mathrm{C}$ and results were always repeated at least three times to check the reproducibility. Then $i_{\text {corr }}$ was used for the calculation of inhibition efficiency and surface coverage $(\theta)$ as below:

$$
\% \mathrm{IE}=\theta \times 100=\left(1-\left(\mathrm{i}_{\text {corr }} / \mathrm{i}^{\circ}{ }_{\text {corr }}\right)\right) \times 100
$$

where $i^{\circ}$ corr and $i_{\text {corr }}$ are corrosion current densities in the absence and presence of inhibitor, respectively.

\subsubsection{Electrochemical impedance spectroscopy (EIS) measurements}

Impedance measurements were carried out using AC signals of $5 \mathrm{mV}$ peak to peak amplitude at the open circuit potential in the frequency range of $100 \mathrm{kHz}$ to $0.1 \mathrm{~Hz}$. All impedance data were fitted to appropriate equivalent circuit using the GamryEchem Analyst software version 6.03.
2.3.3 Electrochemical frequency modulation (EFM) measurements

EFM experiments were performed with applying potential perturbation signal with amplitude $10 \mathrm{mV}$ with two sine waves of 2 and 5 $\mathrm{Hz}$. The choice for the frequencies of 2 and $5 \mathrm{~Hz}$ was based on three arguments [24, 25].The larger peaks were used to calculate the corrosion current density $\left(i_{\text {corr }}\right)$, the Tafel slopes $\left(\beta_{c}\right.$ and $\left.\beta_{a}\right)$ and the causality factors CF-2 and CF-3 [26]. The electrode potential was allowed to stabilize for $30 \mathrm{~min}$ before starting the measurements. All the experiments were conducted at $25^{\circ} \mathrm{C}$. Measurements were performed using Gamry Instrument Potentiostat/ Galvanostat/ ZRA (PCI4-G750). This includes a Gamry framework system v 6.03 Gamry applications include DC 105 software for DC corrosion measurements, EIS 300 software for electrochemical impedance spectroscopy measurements and EFM 140 for electrochemical frequency modulation measurements along with a computer for collecting data. Echem analyst v 6.03 software was used for plotting, graphing, and fitting data.

\subsection{Quantum calculation}

The molecular structures of the investigated compound were optimized initially with PM3 semi empirical method so as to speed up the calculation .All the quantum chemical calculations were performed with Material studio V. 6.0.

\subsection{Scanning electron microscopy measurements (SEM)}

The electrode surface of low carbon steel was examined by scanning electron microscope - type JOEL 840, Japan before and after immersion in $1 \mathrm{M} \mathrm{HCl}$ test solution in the absence and in presence of the optimum concentrations of the investigated inhibitors at $25^{\circ} \mathrm{C}$, for 1 day immersion time. The specimens were washed gently with distilled water, then dried carefully and examined without any further treatments.

\section{Results and discussion}

\subsection{Chemical method (Weight-loss measurements)}

Weight-loss of Mild-steel was determined, at various time intervals, in the absence and presence of different concentrations of Amlodipine Besylate. The obtained weight-loss time curves are represented in Fig (1) The inhibition efficiency of corrosion was found to be dependent on the inhibitor concentration. The curves obtained in the presence of inhibitor fall significantly below that of free acid. In all cases, the increase in the inhibitor concentration was accompanied by a decrease in weight-loss and an increase in the percentage inhibition. These results lead to the conclusion that the compounds under investigation are fairly efficient as inhibitors for low carbon steel 
dissolution in hydrochloric acid solution. Also, the degree of surface coverage $(\Theta)$ by the inhibitor would increase by increasing the inhibitor concentration. In order to get a comparative view, the variation of the percentage inhibition (\% IE) of the inhibitor with its concentrations was calculated and its values obtained are summarized in Table (2)

\subsection{Effect of temperature}

The effect of temperature on the corrosion rate of Mild-steel in $1 \mathrm{M} \mathrm{HCl}$ and in presence of different inhibitors concentrations was studied in two temperatures $\left(30\right.$ and $\left.45^{\circ} \mathrm{C}\right)$ using weight loss measurements. As the temperature increases, the rate of corrosion increases and the inhibition efficiency of Amlodipine Besylate decrease as shown in Table (2). The adsorption behavior of Amlodipine Besylate on $\mathrm{HCl}$ surface occurs through physical adsorption.

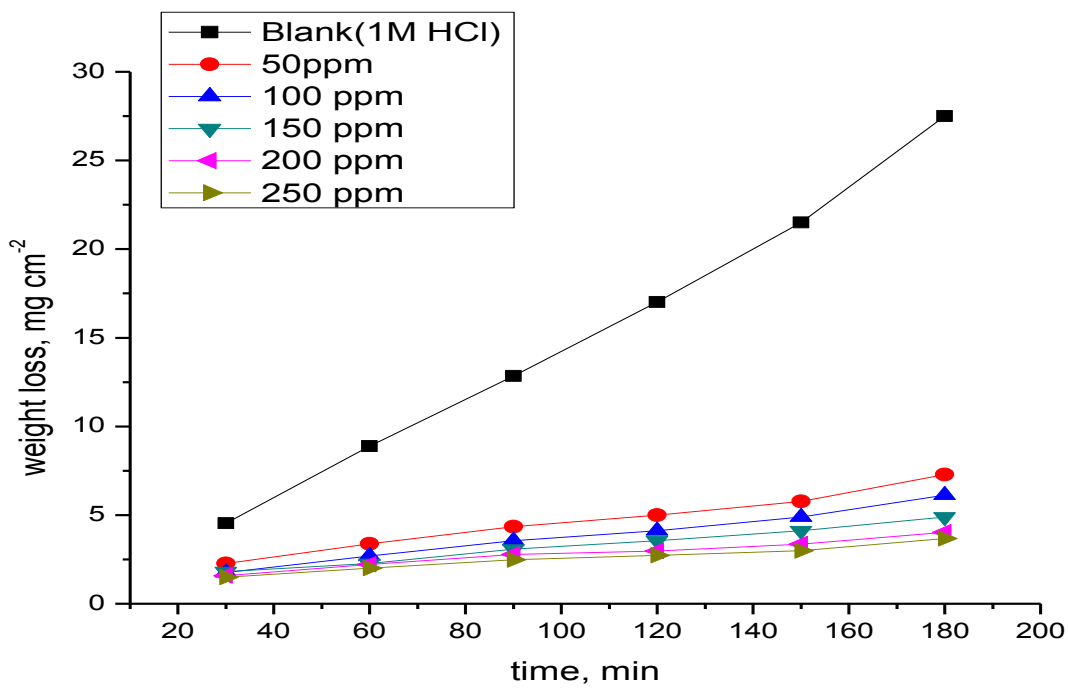

Fig (1) Weight loss-time curves for the corrosion of Mild-steel in $1 \mathrm{M} \mathrm{HCl}$ in the absence and presence of different concentrations of Amlodipine Besylate at $30^{\circ} \mathrm{C}$

Table (1) Data of weight loss measurements for low carbon steel in $1 \mathrm{M} \mathrm{HCl}$ solution in the absence and presence of different concentrations of Amlodipine Besylate at $30^{\circ} \mathrm{C}$

\begin{tabular}{cccc}
\hline Inh] & $\begin{array}{c}\mathbf{C . R} \\
\mathbf{p p m}\end{array}$ & $\boldsymbol{\theta}$ & \% IE \\
\hline Blank $\mathbf{~ c m}^{-\mathbf{2}} \mathbf{m i n}^{-\mathbf{1}}$ & 0.1420 & & \\
50 & 0.0420 & 0.706 & 70.6 \\
100 & 0.0283 & 0.758 & 75.8 \\
150 & 0.0235 & 0.791 & 79.1 \\
200 & 0.0220 & 0.825 & 82.5 \\
250 & 0.0227 & 0.840 & 84.0 \\
\hline
\end{tabular}

Table (2) Inhibition efficiency and corrosion rate (C.R) of Amlodipine Besylate for the corrosion of low carbon steel in $1 \mathrm{M} \mathrm{HCl}$ from weight-loss measurements at different concentrations and temperatures $30 \&$ $45^{\circ} \mathrm{C}$

\begin{tabular}{|c|c|c|c|c|}
\hline \multirow{2}{*}{$\begin{array}{l}\text { [Inh] } \\
\text { ppm }\end{array}$} & \multicolumn{2}{|c|}{$30^{\circ} \mathrm{C}$} & \multicolumn{2}{|c|}{$45^{\circ} \mathrm{C}$} \\
\hline & $\begin{array}{c}\text { C.R } \\
\mathrm{mg} \mathrm{cm}^{-2} \min ^{-1} \\
\end{array}$ & $\%$ IE & $\begin{array}{c}\text { C.R } \\
\mathrm{mg} \mathrm{cm}^{-2} \min ^{-1}\end{array}$ & $\% \mathrm{IE}$ \\
\hline Blank & 0.14 & ----- & 0.46 & ----- \\
\hline 50 & 0.04 & 70.6 & 0.23 & 49.9 \\
\hline 100 & 0.03 & 75.8 & 0.21 & 54.2 \\
\hline 150 & 0.03 & 79.1 & 0.17 & 62.5 \\
\hline 200 & 0.02 & 82.5 & 0.16 & 65.8 \\
\hline 250 & 0.02 & 84.0 & 0.14 & 69.0 \\
\hline
\end{tabular}




\subsection{Adsorption isotherms}

One of the most convenient ways of expressing adsorption quantitatively is by deriving the adsorption isotherm that characterizes the metal/inhibitor/ environment system .Various adsorption isotherms were applied to fit $\Theta$ values but the best fit was found to obey Langmuir adsorption isotherm which is represented in Fig (2) for Amlodipine Besylate, Langmuir adsorption isotherm may be expressed by:

$$
(\mathrm{C} / \theta)=1 / \mathrm{K}_{\mathrm{ads}}+\mathrm{C}
$$

where $\mathrm{C}$ is the concentration $\left(\mathrm{mol} \mathrm{L}^{-1}\right)$ of the inhibitor in the bulk electrolyte, is the degree of surface $\operatorname{coverage}(\theta=\% \quad \mathrm{IE} / 100), \quad \mathrm{K}_{\mathrm{ads}}$ is the adsorption equilibrium constant. A plot of $\mathrm{C}$ versus $\mathrm{C} / \theta$ should give straight line.In order to get a comparative view, the variation of the adsorption equilibrium constant $\left(\mathrm{K}_{\mathrm{ads}}\right)$ of the Amlodipine
Besylatewith its concentration was calculated. The experimental data give good curves fitting for the applied adsorption isotherm as the correlation coefficients $\left(\mathrm{R}^{2}\right)$ were more than 0.99 . The values obtained are given in Table (3). These results confirm the assumption that, this compound is adsorbed on the metal surface through the protonated $(\mathrm{N}, \mathrm{O})$ atoms or via the lone pair of electrons of $(\mathrm{N}, \mathrm{O})$ atoms. The extent of inhibition is directly related to the performance of adsorption layer which is a sensitive function of the molecular structure. The equilibrium constant of adsorption $\mathrm{K}_{\mathrm{ads}}$ obtained from the intercepts of Langmuir adsorption isotherm is related to the free energy of adsorption $\Delta \mathrm{G}^{\circ}$ ads as follows:

$\left.\mathrm{K}_{\mathrm{ads}}=1 / 55.5 \exp \left[-\Delta \mathrm{G}_{\text {ads }}^{\circ}\right] / \mathrm{RT}\right]$

where, 55.5 is the molar concentration of water in the solution in $\mathrm{M}^{-1}$

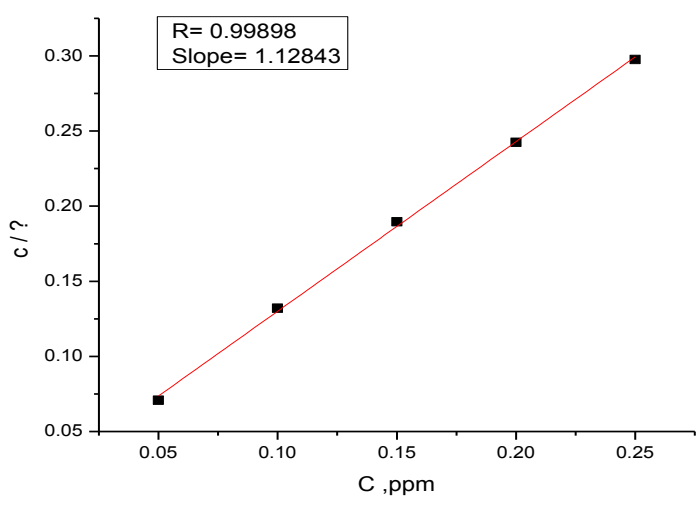

Fig (2) Langmuir adsorption isotherm.

Table (3) clearly shows a good dependence of $\Delta \mathrm{G}^{\mathrm{o}}$ ads on $\mathrm{T}$, indicating the good correlation among thermodynamic parameters. The negative value of $\Delta \mathrm{G}_{\text {ads }}^{\mathrm{o}}$ reflect that the adsorption of studied compound on low carbon steel surface from $1 \mathrm{M}$ $\mathrm{HCl}$ solution is spontaneous process and stability of the adsorbed layer on the low carbon steel surface. Generally, values of $\Delta \mathrm{G}_{\text {ads }}^{\mathrm{o}}$ around $-20 \mathrm{~kJ} \mathrm{~mol}^{-1}$ or lower are consistent with the electrostatic interaction between the charged molecules and the charged metal (physical adsorption); those around $40 \mathrm{~kJ} \mathrm{~mol}^{1}{ }^{1}$ or higher involves charge sharing or transfer from organic molecules to the metal surface to form a coordinate type of bond (chemisorption) [27]. From the obtained values of $\Delta \mathrm{G}^{\circ}{ }_{\text {ads }}$ it was found the existence of physicaladsorption. The unshared electron pairs in oxygen, and nitrogen may interact with d-orbitals of low carbon steel to provide a protective physical adsorbed film [28]. The values of thermodynamic parameter for the adsorption of tested compound can provide valuable information about the mechanism of corrosion inhibition.An estimate of heat of adsorption was obtained from the trend of surface coverage with temperature as follow [29]:

$\mathrm{Q}_{\mathrm{ads}}=$

2.303R

$\left[\log \left(\frac{\theta_{2}}{1-\theta_{2}}\right)-\log \left(\frac{\theta_{1}}{1-\theta_{1}}\right)\right] x\left(\frac{T_{1} x T_{2}}{T_{2}-T_{1}}\right)$

Where $\theta_{1}$ and $\theta_{2}$ are the degree of surface coverage at temperature $T_{1}$ and $T_{2}$, The calculated values for both parameters are given in Table 4.

Table (3) Thermodynamic parameters for the adsorption on Low carbon steel surface in $1 \mathrm{MHCl}$ at different

\begin{tabular}{|c|c|c|c|c|}
\hline $\begin{array}{l}\text { Temperature } \\
{ }^{\circ} \mathrm{C}\end{array}$ & $\begin{array}{l}\mathbf{K}_{\mathrm{ads}} \\
\mathbf{M}^{-1}\end{array}$ & $\begin{array}{l}-\Delta \mathrm{G}^{\mathrm{o}} \text { ads } \\
\mathbf{k J} \mathrm{mol}^{-1}\end{array}$ & $\begin{array}{c}\Delta \mathbf{H}_{\text {ads }}^{\mathbf{a}} \\
\mathbf{k J} \mathrm{mol}^{-1}\end{array}$ & $\mathbf{R}^{2}$ \\
\hline 30 & 57.91 & 20.3 & ------ & 0.99898 \\
\hline 45 & 21.87 & 18.8 & 45.4 & 0.99187 \\
\hline
\end{tabular}




\subsection{Kinetic - thermodynamic corrosion parameter}

The effect of temperature on corrosion inhibition of low carbon steel in $1 \mathrm{M} \mathrm{HCl}$ solution in the absence and presence of different concentrations of investigated compound at different temperatures 30 and $45^{\circ} \mathrm{C}$ was studied using weight loss measurements. The corrosion rate was found to increase with increasing temperature both in uninhibited and inhibited solutions. The apparent activation energy $\left(\mathrm{E}_{\mathrm{a}}^{*}\right)$ for the corrosion process can be calculated from Arrhenius-type:

$$
\log \rho_{2} / \rho_{1}=\left(E^{*}{ }_{a} / 2.303 R\right) \times\left(\frac{1}{T_{1}}-\frac{1}{T_{2}}\right)
$$

where $\mathrm{E}_{\mathrm{a}}^{*}$ is the apparent activation corrosion energy, $\mathrm{R}$ is the universal gas constant, $\rho_{1}, \rho_{2}$ are corrosion rates at temperature $T_{1}, T_{2}$ respectively

The calculated values of $\mathrm{E}_{\mathrm{a}}{ }^{*}$ are $63.5 \mathrm{~kJ} \mathrm{~mol}^{-1}$ for blank and $72.2 \mathrm{~kJ} \mathrm{~mol}^{-1}$ in presence of investigated compound. The value of $\mathrm{E}_{\mathrm{a}}{ }^{*}$ determined in solution containing the investigated compound is higher than that in its absence.

The decrease in \% IE values as the temperature is increased and high values of $E_{a}{ }^{*}$ in presence of the investigated compound can be interpreted as an indication for a physical or columbic type of adsorption [30]. The high $\mathrm{E}_{\mathrm{a}}{ }^{*}$ value in the inhibited solution can be correlated with the increased thickness of the double layer, which enhances the activation energy of the corrosion process.

\subsection{Potentiodynamicpolarization measurements}

Fig (3) shows typical polarization curves for Low carbon steel in $1 \mathrm{M} \mathrm{HCl}$ media. In the presence of Amlodipine Besylate, both the cathodic and anodic current densities were greatly decreased over a wide potential range.Various corrosion parameters such as corrosion potential $\left(\mathrm{E}_{\text {corr }}\right)$, anodic and cathodicTafel slopes $\left(\beta_{\mathrm{a}}, \beta_{\mathrm{c}}\right)$, the corrosion current density $\left(i_{\text {corr }}\right)$, the degree of surface coverage $(\theta)$ and the inhibition efficiency (\%IE) are given in Table (5). It can be seen from the experimental results that in all cases, addition of Amlodipine Besylate induced a significant decrease in cathode and anodic currents. The values of $\mathrm{E}_{\text {corr }}$ were affected and slightly changed by the addition of Amlodipine Besylate. This indicates that Amlodipine Besylateacts as mixed-type inhibitor. The slopes of anodic and cathodicTafel lines $\left(\beta_{\mathrm{a}}\right.$ and $\beta_{c}$ ), were slightly changed (Tafel lines are parallel), on increasing the concentration of the tested compound which indicates that there is no change of the mechanism of inhibition in the presence and absence of Amlodipine Besylate. The order of inhibition efficiency of Amlodipine Besylateat different concentrations as given by polarization measurements are listed in Table (5) . The results are in good agreement with those obtained from weight-loss measurements.

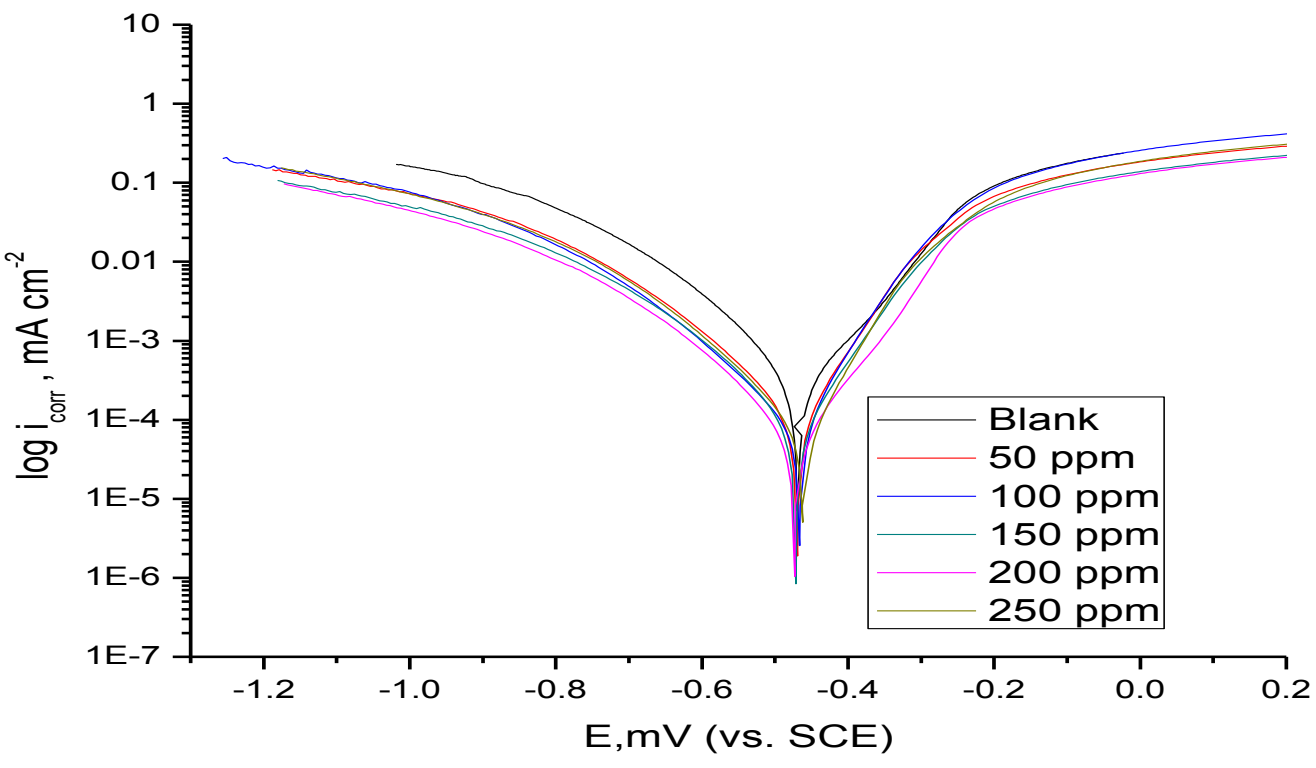

Fig (2) Potentiodynamic polarization curves for the dissolution of low carbon steel in $1 \mathrm{M}$ $\mathrm{HCl}$ in the absence and presence of different concentrations of Amlodipine Besylate at $30^{\circ} \mathrm{C}$ 
Evaluation of an Expired Non-Toxic Amlodipine Besylatedrug as Corrosion

Table (5) Corrosion potential $\left(\mathrm{E}_{\text {corr }}\right)$, corrosion current density $\left(\mathrm{i}_{\text {corr }}\right)$, Tafel slopes $\left(\beta_{\mathrm{c}}, \beta_{\mathrm{a}}\right)$, degree of surface coverage $(\theta)$, and inhibition efficiency (\% IE) of low carbon steel in $1 \mathrm{M} \mathrm{HCl}$ at $30^{\circ} \mathrm{C}$ for Amlodipine Besylate

\begin{tabular}{|c|c|c|c|c|c|c|c|}
\hline $\begin{array}{l}\text { [Inh.] } \\
\text { ppm }\end{array}$ & $\begin{array}{c}\text {-EcorrmV } \\
\text { vsSCE }\end{array}$ & $\begin{array}{r}\mathbf{i}_{\text {corr }} \times 10^{-4} \\
\mu \mathrm{A} \mathrm{cm}\end{array}$ & $\beta_{\mathrm{c}} \mathrm{mV} \operatorname{dec}^{-1}$ & $\beta_{\mathrm{a}} \mathrm{mV} \operatorname{dec}^{-1}$ & CRmpy & $\boldsymbol{\theta}$ & $\%$ IE \\
\hline Blank & 469 & 301.0 & 117 & 116 & 137.40 & ------ & ----- \\
\hline 50 & 470 & 105.0 & 118 & 79 & 47.82 & 0.651 & 65.1 \\
\hline 100 & 466 & 85.9 & 128 & 71 & 39.24 & 0.715 & 71.5 \\
\hline 150 & 471 & 84.5 & 120 & 83 & 38.59 & 0.719 & 71.9 \\
\hline 200 & 472 & 63.1 & 118 & 96 & 28.83 & 0.790 & 79.0 \\
\hline 250 & 462 & 49.7 & 79 & 63 & 22.70 & 0.835 & 83.5 \\
\hline
\end{tabular}

\subsection{Electrochemical impedance spectroscopy (EIS) measurements}

EIS is well-established and it is powerful technique for studying the corrosion. Surface properties, electrode kinetics and mechanistic information can be obtained from impedance diagrams. Fig (4) shows the Nyquist(a) and Bode(b) plots obtained at open-circuit potential both in the absence and presence of increasing concentrations of investigated compounds at $30^{\circ} \mathrm{C}$. The increase in the size of the capacitive loop with the addition of investigated compound shows that a barrier gradually forms on the low carbon steel surface Fig (4a) Bode plots Fig (4b), shows that the total impedance increases with increasing inhibitor concentration $(\log \mathrm{Z}$ vs. $\log \mathrm{f})$. But $(\log \mathrm{f}$ vs. phase), also Bode plot shows the continuous increase in the phase angle shift, obviously correlating with the increase of inhibitor adsorbed on low carbon steel surface. The Nyquist plots do not yield perfect semicircles as expected from the theory of EIS. The deviation from ideal semicircle was generally attributed to the frequency dispersion [31] as well as to the inhomogenities of the surface.EIS spectra of the investigated compounds were analyzed using the equivalent circuit, Fig (5), which represents a single charge transfer reaction and fits well with our experimental results. The constant phase element, CPE, is introduced in the circuit instead of a pure double layer capacitor to give a more accurate fit [32]. The double layer capacitance, $\mathrm{C}_{\mathrm{dl}}$, for a circuit including a CPE parameter ( $\mathrm{Y} 0$ and $\mathrm{n}$ ) were calculated from eq.14 [33]:

$$
\mathrm{Cdl}=\mathrm{Y}_{0}\left(\omega_{\max }\right)^{\mathrm{n}-1}
$$

where $Y_{0}$ is the magnitude of the CPE, $\omega_{\max }=$ $2 \pi f_{\max }, f_{\max }$ is the frequency at which the imaginary component of the impedance is maximal and the factor $\mathrm{n}$ is an adjust table parameter that usually lies between 0.50 and 1.0. After analyzing the shape of the Nyquist plots, it is concluded that the curves approximated by a single capacitive semicircles, showing that the corrosion process was mainly charged-transfer controlled [34, 35].The general shape of the curves is very similar for all samples (in presence or absence of inhibitor at different immersion times) indicating that no change in the corrosion mechanism [36]. From the impedance data Table (6), we concluded that the value of $R_{c t}$ increases with increasing the concentration of Amlodipine Besylate and this indicates an increase in $\% \mathrm{IE}_{\mathrm{EIS}}$, which in concord with the previous results obtained. In fact the presence of Amlodipine Besylateenhances the value of $R_{c t}$ in acidic solution. Values of double layer capacitance are also brought down to the maximum extent in the presence of Amlodipine Besylate and the decrease in the values of CPE follows the order similar to that obtained for $\mathrm{i}_{\text {corr }}$ in this study. The decrease in $\mathrm{CPE} / \mathrm{C}_{\mathrm{dl}}$ results from a decrease in local dielectric constant and/or an increase in the thickness of the double layer, suggesting that organic derivatives inhibit the low carbon steel corrosion by adsorption at metal/acid [37].The inhibition efficiency was calculated from the charge transfer resistance data from eq.15 [38]:

$$
\% \mathrm{IE}_{\mathrm{EIS}}=\left[1-\left(\mathrm{R}^{\circ} \mathrm{ct} / \mathrm{R}_{\mathrm{ct}}\right)\right] \times 100
$$

where $\mathrm{R}_{\mathrm{ct}}^{\mathrm{o}}$ and Rct are the charge-transfer resistance values without and with inhibitor respectively 


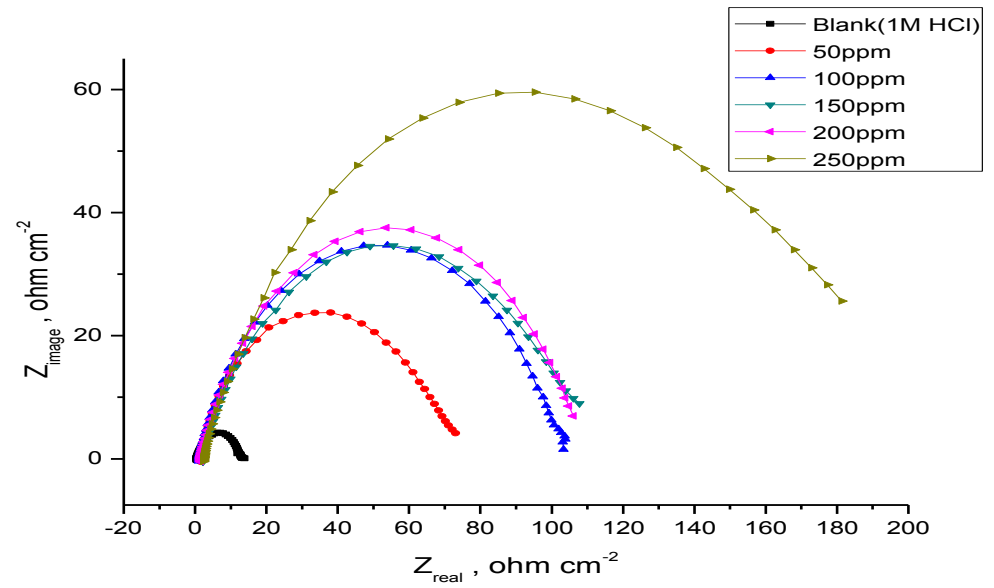

Fig (4a) The Nyquist plots for the corrosion of low carbon steel in $1 \mathrm{M}$ $\mathrm{HCl}$ in the absence and presence of different concentrations of Amlodipine Besylate at $30^{\circ} \mathrm{C}$

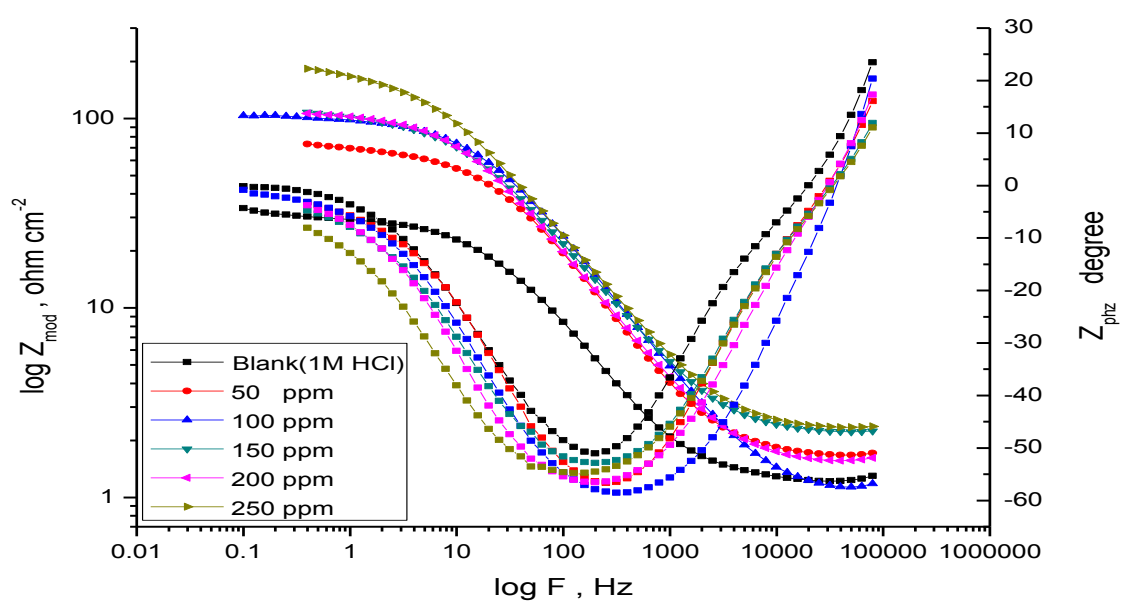

Fig (4b) The Bode plots for the corrosion of low carbon steel in $1 \mathrm{M}$ $\mathrm{HCl}$ in the absence and presence of different concentrations of Amlodipine Besylate at $30^{\circ} \mathrm{C}$.

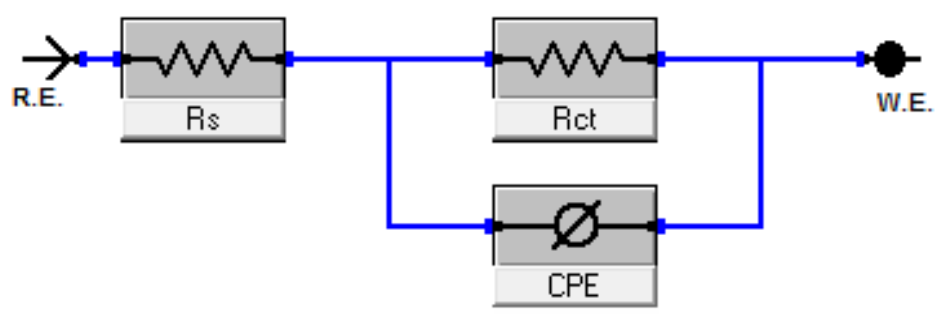

Fig 5. Equivalent circuit model used to fit experimental EIS

Table (6) Electrochemicalkinetic parameters obtained by EIS technique for in $1 \mathrm{M} \mathrm{HCl}$ without and with various concentrations of Amlodipine Besylate at $30^{\circ} \mathrm{C}$

\begin{tabular}{|c|c|c|c|c|}
\hline $\begin{array}{l}\text { [Inh.] } \\
\text { ppm }\end{array}$ & $\begin{array}{c}\mathrm{C}_{\mathrm{dl}} \times \mathbf{1 0}^{4} \\
\mathrm{~F} \mathrm{~cm}^{-2}\end{array}$ & $\begin{array}{c}R_{\mathbf{P}} \\
\Omega \mathrm{cm}^{2}\end{array}$ & $\boldsymbol{\theta}$ & $\%$ IE \\
\hline Blank & 5.38 & 16.71 & --- & --- \\
\hline 50 & 5.00 & 96.55 & 0.827 & 82.7 \\
\hline 100 & 3.59 & 116.20 & 0.856 & 85.6 \\
\hline 150 & 3.72 & 144.50 & 0.884 & 88.4 \\
\hline 200 & 1.75 & 160.00 & 0.896 & 89.6 \\
\hline 250 & 1.67 & 291.70 & 0.943 & 94.3 \\
\hline
\end{tabular}




\subsection{Electrochemical frequency modulation (EFM) measurements}

EFM is a nondestructive corrosion measurement technique that can directly and quickly determine the corrosion current values without prior knowledge of Tafel slopes, and with only a small polarizing signal. These advantages of EFM technique make it an ideal candidate for online corrosion monitoring [39].The great strength of the EFM is the causality factors which serve as an internal check on the validity of EFM measurement. The causality factors $\mathrm{CF}-2$ and $\mathrm{CF}$ 3 are calculated from the frequency spectrum of the current responses.Fig (6) shows the EFM Intermodulation spectra (current vs frequency) of low carbon steel in $\mathrm{HCl}$ solution containing different concentrations of Amlodipine Besylate. The harmonic and intermodulation peaks are clearly visible and are much larger than the background noise.The larger peaks were used to calculate the corrosion current density $\left(\mathrm{i}_{\text {corr }}\right)$, the Tafel slopes $\left(\beta_{\mathrm{c}}\right.$ and $\left.\beta_{\mathrm{a}}\right)$ and the causality factors (CF-2 and CF-3).These electrochemical parameters were listed in Table 8.The data presented in Table (8) obviously show that, the addition of the tested compound at a given concentration to the acidic solution decreases the corrosion currentdensity, indicating that this compound inhibits the corrosion of low carbon steel in $1 \mathrm{M} \mathrm{HCl}$ through adsorption. The causality factors obtained under different experimental conditions are approximately equal to the theoretical values (2 and 3) indicating that the measured data are verified and of good quality. The inhibition efficiencies $\% \mathrm{IE}_{\mathrm{EFM}}$ increase by increasing the inhibitor concentration and was calculated as from Eq.2

Table (8) Electrochemical kinetic parameters obtained from EFM technique for low carbon steel in $1 \mathrm{M} \mathrm{HCl}$ in the absence and presence of different concentrations of Amlodipine Besylateat $30^{\circ} \mathrm{C}$

\begin{tabular}{lcccccccc}
\hline $\begin{array}{l}{[\mathbf{I n h}]} \\
\mathbf{p p m}\end{array}$ & $\begin{array}{c}\mathbf{i}_{\text {corr }}, \boldsymbol{\mu} \mathbf{A} \\
\mathbf{c m}^{\mathbf{2}}\end{array}$ & $\begin{array}{c}\boldsymbol{\beta}_{\mathbf{a}}, \mathbf{m V} \\
\mathbf{d e c}^{-1}\end{array}$ & $\begin{array}{c}\boldsymbol{\beta}_{\mathbf{c}}, \mathbf{m V} \\
\mathbf{d e c}^{-\mathbf{1}}\end{array}$ & $\mathbf{C F - 2}$ & $\mathbf{C F - 3}$ & $\mathbf{C R} \mathbf{m p y}$ & $\Theta$ & $\%$ IE \\
\hline Blank & 700.4 & 104.80 & 124 & 1.94 & 2.79 & 7.37 & & $-\cdots$ \\
50 & 308.8 & 91.450 & 121 & 1.92 & 2.88 & 0.23 & 0.600 & 60.0 \\
100 & 274.4 & 89.140 & 204.4 & 1.97 & 3.17 & 1.76 & 0.610 & 61.0 \\
150 & 210.2 & 85.760 & 120.3 & 1.94 & 2.77 & 0.62 & 0.700 & 70.0 \\
200 & 205.7 & 89.040 & 123.3 & 1.95 & 3.12 & 1.26 & 0.710 & 71.0 \\
250 & 127.9 & 93.020 & 133.5 & 1.94 & 2.85 & 0.81 & 0.820 & 82.0
\end{tabular}

\subsection{Surface examinations}

Scanning electron microscope (SEM) and energy dispersive X-ray (EDX) experiments were carried out in order to verify if the investigated compound is in fact adsorbed on low carbon steel surface or just peeled off the surface. SEM images were indicative of the changes that accompany both corrosion and protection of the low carbon steel surface Fig $7 a-7$ c). Fig (7a) shows the free metal while Fig (7b) shows the damage caused to the surface by hydrochloric acid. Fig (7) c,shows SEM images of the low carbon steel surface after treatment with $1 \mathrm{M}$ $\mathrm{HCl}$ containing $150 \mathrm{ppm}$ of inhibitor. From these images, it is obvious that the steel surface seems to be almost unaffected by corrosion. This is because of adsorption of inhibitor, forming a thin protective film of the inhibitor on the metal surface. This film is responsible for the highly efficient inhibition by this inhibitor.The corresponding EDX profile analyses are presented in Table (9) and Fig (8) for investigated compound. It is also important to notice the existence of $\mathrm{C}$ and $\mathrm{N}$ peaks in the EDX spectra of the low carbon steel surface corresponding to the samples immersed for 1 day in solutions containing the optimum concentration of this compound. The formation of a thin inhibitor film is in agreement with the SEM observations.

\subsection{Quantumcalculations}

The energy of highest occupied molecular orbital $\left(\mathrm{E}_{\mathrm{HOMO}}\right)$ indicates the ability of the molecule to donate electrons $(-8.962 \mathrm{eV})$ to an appropriated acceptor with empty molecular orbitals, whereas the energy of unoccupied molecular orbital $\left(\mathrm{E}_{\mathrm{LUMO}}\right)$ indicates its ability to accept electrons $(-0.472 \mathrm{eV})$. The lower the value of $E_{\text {LUMO }}$, the more ability of the molecule is to accept electrons [40]. The higher the value of $\mathrm{E}_{\mathrm{HOMO}}$ of the inhibitor, the easier is its ability to offer electrons to the unoccupied d-orbital of metal surface, and the greater is its inhibition efficiency .

The $\mathrm{E}_{\mathrm{HOMO}}-\mathrm{E}_{\mathrm{LumO}}$ energy gap, $\Delta \mathrm{E}$ approach, $(8.490 \mathrm{eV})$ which is an important stability index, is applied to develop theoretical models for explaining the structure and conformation barriers in many molecular systems. The smaller the value of $\Delta \mathrm{E}$, the more is the probable inhibition efficiency the compound has [41] Variation in the inhibition efficiency of the inhibitor depends on the presence of electronegative $\mathrm{O}$ - and $\mathrm{N}$ - atoms as substituent in their molecular structure. The calculated charges of selected atoms are presented in Fig (9) . 

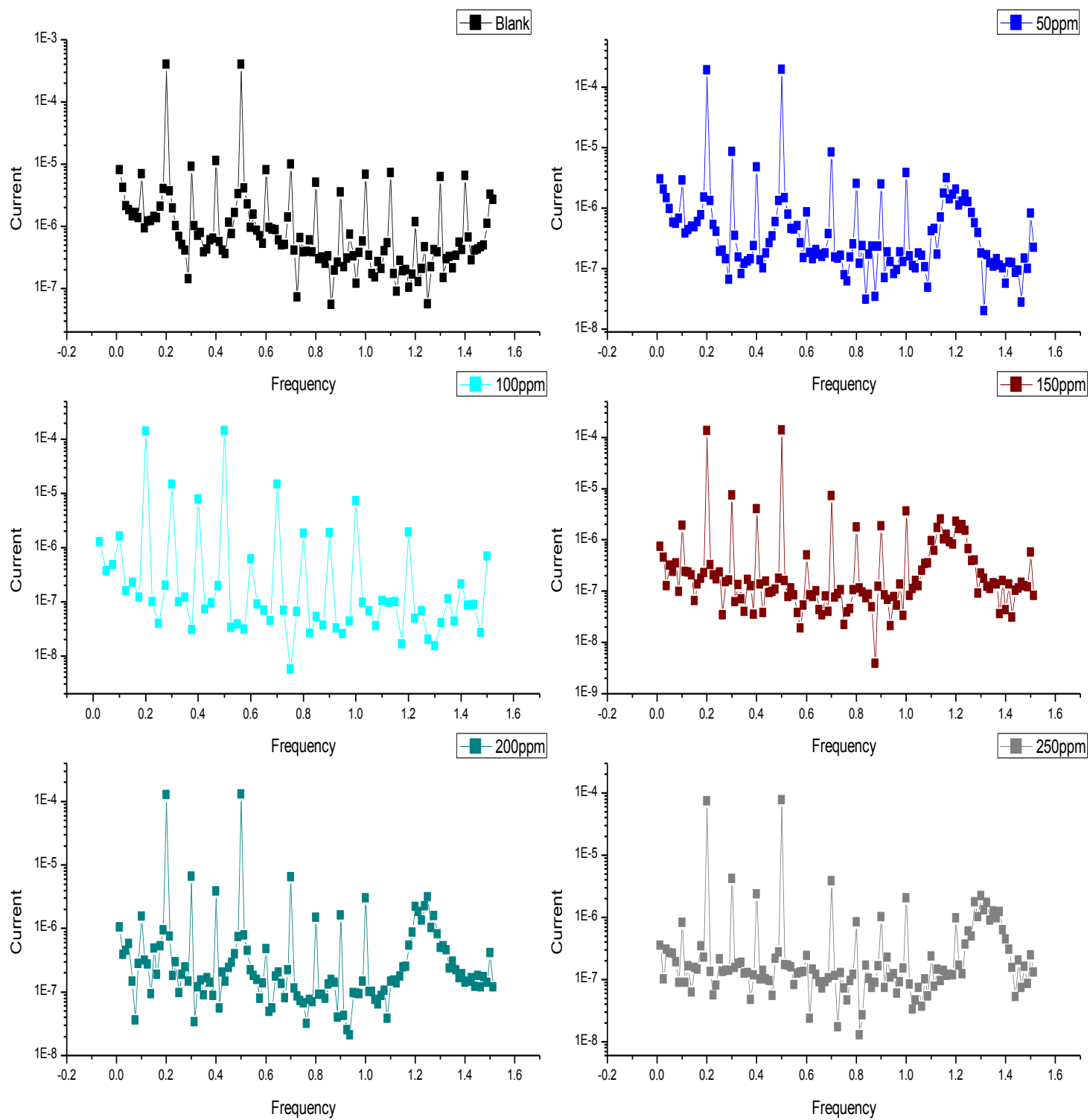

Fig (6) EFM spectra for low carbon steel in $1 \mathrm{M}$ HClin the absence and presence of different concentrations of Amlodipine Besylate at $30^{\circ} \mathrm{C}$

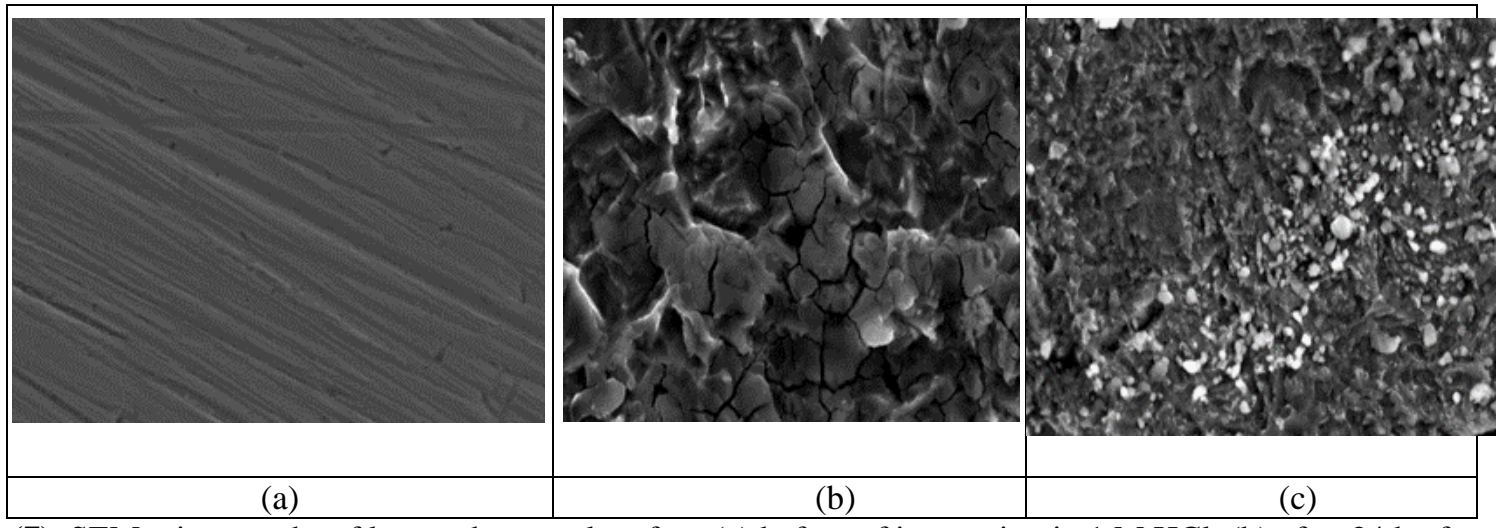

Fig (7) SEM micrographs of low carbon steel surface (a) before of immersion in $1 \mathrm{M} \mathrm{HCl}$, (b) after $24 \mathrm{~h}$ of immersion in $1 \mathrm{M} \mathrm{HCl}$, (c) after $24 \mathrm{~h}$ of immersion in $1 \mathrm{M} \mathrm{HCl}+150 \mathrm{ppm}$ of Amlodipine Besylate. 


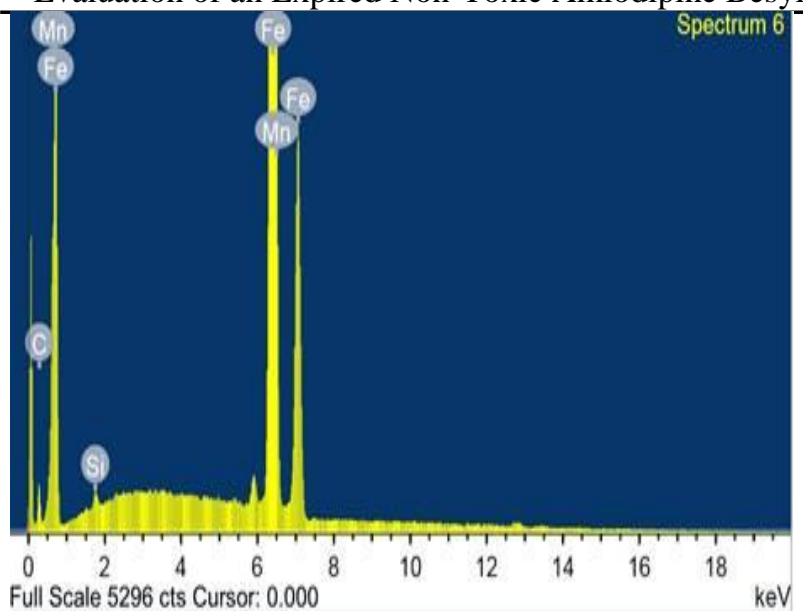

(a)

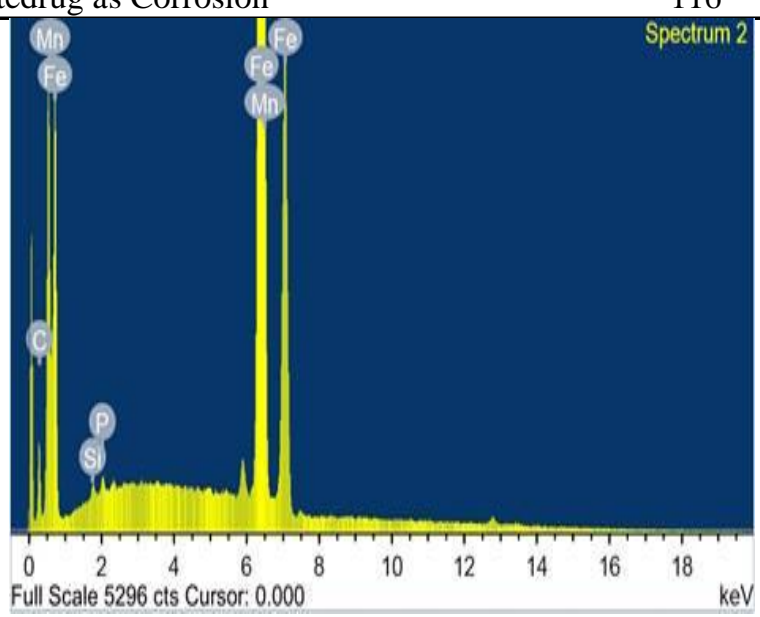

(b)

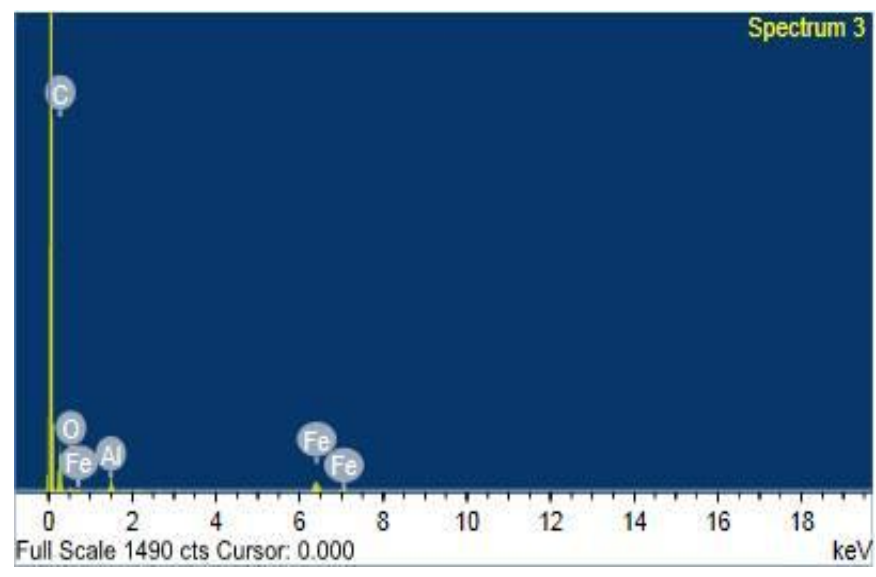

(c)

Fig (8) EDX spectra of low carbon steel in $1 \mathrm{M} \mathrm{HCl}(\mathrm{a})$ before of immersion in $1 \mathrm{M} \mathrm{HCl}$, (b) after $24 \mathrm{~h}$ of immersion in $1 \mathrm{M} \mathrm{HCl}$, (c) after $24 \mathrm{~h}$ of immersion in $1 \mathrm{M} \mathrm{HCl}+150 \mathrm{ppm}$ of Amlodipine Besylate

\subsection{Mechanism of corrosion inhibition}

The inhibition mechanism involves the adsorption of the inhibitor on the metal surface immersed in aqueous HClsolution. Four types of adsorption [42] may take place involving organic molecules at the metal-solution interface: 1)Electrostatic attraction between the charged molecules and the charged metal; 2) Interaction of unshared electron pairs in the molecule with the metal; 3) Interaction of $\pi$-electrons with the metal; 4) Combination of all the above. From the observations drawn from the different methods, corrosion inhibition of low carbon steel in $1 \mathrm{M} \mathrm{HCl}$ solutions by the investigated inhibitor as indicated from weight loss, potentiodynamic polarization and EIS techniques were found to depend on the concentration and the nature of the inhibitor.Amlodipine Besylatecontain polar groups such as oxygen, nitrogen. Each atom is chemisorption center and the inhibition efficiency depends on the electron density around the chemisorption center; higher the electron density at the chemisorption center, greater is the inhibition efficiency.This inhibitor has high inhibition efficiency as it has an oxygen and $\mathrm{N}$ atoms with lone pair of electrons. These electrons interact with the vacant d-orbital of iron present in the low carbon steel surface and adsorb strongly there by blocking more number of adsorption sites on the low carbon steel surface. Presence of oxygen and nitrogen caused resonance effect which facilitate stronger adsorption of inhibitor on low carbon steel surface. This lead to high IE forAmlodipine Besylate. It has been previously reported in literature, that inhibiting effect depends mainly on inhibitor concentration, the molecular structure, size and structure of the side chain in the organic compounds 


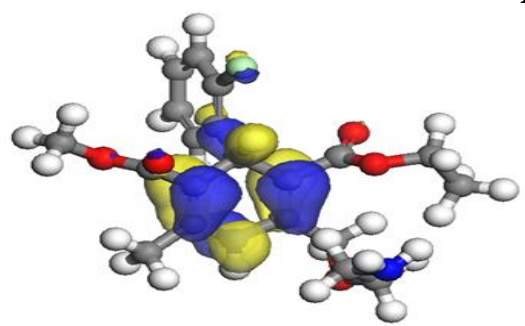

HOMO

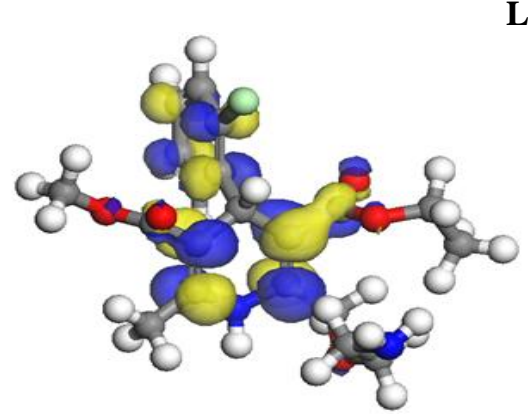

LUMO
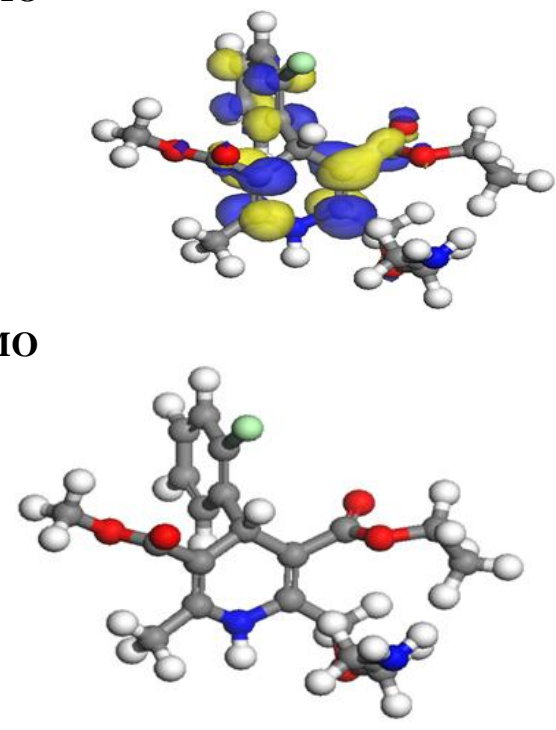

Fig (9) Optimized molecular structure of inhibitor, and their frontier molecular orbital density distribution (HOMO and LUMO).

\section{Conclusions}

From the overall experimental results the following conclusions can be deduced:

1. The investigated compound is good inhibitor and acts as mixed type inhibitor for low carbon steel corrosion in $1 \mathrm{M} \mathrm{HCl}$ solution.

2. Reasonably good agreement was observed between the values obtained by the weight loss and electrochemical measurements were in good agreement.

3. The results obtained from all electrochemical measurements showed that the inhibiting action increases with the inhibitor concentration and decreases with the increasing in temperature.

4. Double layer capacitances decrease with respect to blank solution when the inhibitor is added. This fact confirms the adsorption of these molecules on the low carbon steel surface.

5. The thermodynamic parameters revealed that the inhibition of corrosion by investigated compound is due to the formation of a physical adsorbed film on the metal surface.

6. The adsorption of inhibitor on low carbon steel surface in $\mathrm{HCl}$ solution follows Langmuir isotherm for the compound.

7. The values of inhibition efficiency obtained from the different independent quantitative techniques used show the validity of the results.

8. Quantum chemical parameters for this investigated compound were calculated to provide further insight into the mechanism of inhibition of the corrosion process

\section{References}

[1] Tianbao Du, Jiajian Chen, Dianzhen Cao, N,NDipropynoxy methyl amine trimethylphosphonate as corrosion inhibitor for iron in sulfuric acid J. Mater. Sci. 36 pp.39033907, 2001.

[2] P.Morales-Gil, G.Negron-Silva, M.RomeroRomo, C.Angeles-Chavez, M.Palomar-Pardave, Corrosion inhibition of pipeline steel grade API $5 \mathrm{~L}$ X52 immersed in a $1 \mathrm{M} \mathrm{H}_{2} \mathrm{SO}_{4}$ aqueous solution using heterocyclic organic molecules, Electrochim. Acta.49 pp.4733- 4741, 2004.

[3] J.M.Bastidas, J.L.Polo, E.Cano, Substitutional inhibition mechanism of mild steel hydrochloric acid corrosion by hexylamine and dodecylamine, J. Appl. Electrochem, vol.30, pp.1173-1177, 2000.

[4] B.Zerga, A.Attiyibat, M.Sfaira, M.Taleb, B.Hammouti, M.EbnTouhami, S.Radi, Z.Rais, Effect of some tripodalbipyrazolic compounds on C38 steel corrosion in hydrochloric acid solution, J. Appl. Electrochem. Vol.40, pp.1575-1582, 2010.

[5] S.T.Selvi, V.Raman, N.Rajendran, Corrosion inhibition of mild steel by benzotriazole derivatives in acidic medium, J. Appl. Electrochem. Vol.33, pp.1175-1182, 2003.

[6] P.Lowmunkhong, D.Ungthararak, P.Sutthivaiyakit, Tryptamine as a corrosion inhibitor of mild steel in hydrochloric acid solution, Corros. Sci. vol.52, pp.30-36, 2010.

[7] M.Zerfaoui, H.Oudda, B.Hammouti, S.Kertit, M.Benkaddour, Inhibition of corrosion of iron in citric acid media by aminoacids, Prog. Org. Coat. Vol.51, pp.134-138, 2004. 
[8] A.Chetaouani, B.Hammouti, A.Aouniti, N.Benchat, T.Benhadda, New synthesisedpyridazine derivatives as effective inhibitors for the corrosion of pure iron in $\mathrm{HCl}$ medium, Prog. Org. Coat. Vol.45, pp.373-378, 2002.

[9] K.M.Awad, Semiempirical investigation of the inhibition efficiency of thiourea derivatives as corrosion inhibitors, J. Electroanal. Chem. Vol.567, pp.219-225, 2004.

[10] D.K.Yadav, B.Maiti, M.A.Quraishi, Electrochemical and quantum chemical studies of 3,4-dihydropyrimidin-2(1H)-ones as corrosion inhibitors for mild steel in hydrochloric acid solution, Corros. Sci. vol.52, pp.3586-3598, 2010.

[11] K.S.Jacob, G.Parameswaran, Corrosion inhibition of mild steel in hydrochloric acid solution by Schiff base furointhiosemicarbazone, Corros. Sci. vol.52, pp.224-228, 2010

[12] A.Ostovari, S.M.Hoseinieh, M.Peikari, S.R.Shadizadeh, S.J.Hashemi, Corrosion inhibition of mild steel in $1 \mathrm{M} \mathrm{HCl}$ solution by henna extract: A comparative study of the inhibition by henna and its constituents (Lawsone, Gallic acid, $\alpha$-D-Glucose and Tannic acid) Corros.Sci. vol.51, pp.1935-1949, 2009.

[13] F.C.Giacomelli, C.Giacomelli, M.F.Amadori, V.Schmidt, A.Spinelli, Inhibitor effect of succinic acid on the corrosion resistance of mild steel: electrochemical, gravimetric and optical microscopic studies, Mater. Chem. Phys. Vol.83, pp.124-128, 2004.

[14] A.K.Satapathy, G.Gunasekaran, S.C.Sahoo, K.Amit, P.V.Rodrigues, Corrosion inhibition by Justiciagendarussa plant extract in hydrochloric acid solution, Corros. Sci. 51 , pp.2848-2856, 2009

[15] X.H.Li, S.D.Deng, H.Fu, Inhibition by JasminumnudiflorumLindl.leaves extract of the corrosion of cold rolled steel in hydrochloric acid solution, J.Appl. Electrochem. Vol.40, pp.1641-1649, 2010.

[16] P.Lima-Neto, A.P.Araujo, W.S.Araujo, A.N.Correia, Study of the anticorrosive behaviour of epoxy binders containing nontoxic inorganic corrosion inhibitor pigments, Prog. Org. Coat. Vol.62, 344-350, 2008.

[17] I.B.Obot, N.O.Obi-Egbedi, S.A.Umoren, Antifungal drugs as corrosion inhibitors for aluminium in $0.1 \mathrm{M} \mathrm{HCl}$,Corros. Sci. vol.51, pp.1868-1875, 2009.

[18] M.Abdallah, Antibacterial drugs as corrosion inhibitors for corrosion of aluminium in hydrochloric solution , Corros. Sci. vol.46, pp.1981-1996, 2004.

[19] A.S.Fouda, A.A.Al-Sarawy, F.Sh.Ahmed, H.M.El-Abbasy, Corrosion inhibition of aluminum 6063 using some pharmaceutical compounds, Corros. Sci. vol.51, pp.485-492, 2009.

[20] I.B.Obot, N.O.Obi-Egbedi, inhibitory effect and adsorption characteristics of 2,3diaminonaphthalene at aluminum/hydrochloric acid interface: experimental and theoretical study Surf. Rev. Lett. 15, pp.903-910, 2008.

[21] A.S.Fouda , M.N.EL-Haddad and Y.M.Abdallah, Septazole: Antibacterial Drug as a Green Corrosion Inhibitor for Copper in Hydrochloric Acid Solutions, International Journal of Innovative Research in Science, Engineering and Technology, pp.7073-7085, Vol.2 (12), December 2013.

[22] Imran Naqvi, A.R.Saleemi, S.Naveed, Cefixime: A drug as Efficient Corrosion Inhibitor for Low carbon steel in Acidic Media. Electrochemical and Thermodynamic Studies, Int. J. Electrochem. Sci., vol.6, pp.146 - 161, 2011.

[23] E.E.Oguzie :Corrosion inhibition of mild steel in hydrochloric acid solution by methylene blue dye, Mater. Letters, vol.59, pp.1076-1079, 2005.

[24] K.F.Khaled,Application of electrochemical frequency modulation for monitoring corrosion and corrosion inhibition of iron by some indole derivatives in molar hydrochloric acid, Mater. Chem. Phys., vol.112, pp.290-300, 2008.

[25] K.F.Khaled.Evaluation of electrochemical frequency modulation as a new technique for monitoring corrosion and corrosion inhibition of carbon steel in perchloric acid using hydrazine carbodithioic acid derivatives, J. Appl. Electrochem., vol.39 pp.429-438, 2009.

[26] S.S.Abdel-Rehim, K.F.Khaled, N.S.AbdElshafi,Electrochemical frequency modulation as a new technique for monitoring corrosion inhibition of iron in acid media by new thiourea derivative, Electrochim. Acta , vol.51, pp.32693277, 2006.

[27] A.Yurt, G.Bereket, A.Kivrak, A.Balaban \& B.Erk, Effect of Schiff Bases Containing Pyridyl Group as Corrosion Inhibitors for Low Carbon Steel in $0.1 \mathrm{M} \mathrm{HCl}, \mathrm{J}$ ApplElectrochem, vol.35, pp.1025-1032, 2005.

[28] F.Bentiss, M.Traisnel \& M.Lagrenee,The substituted 1,3,4-oxadiazoles: a new class of corrosion inhibitors of mild steel in acidic media, Corros Sci., vol.42, pp.127-146, 2000.

[29] G.Gao, and C.Liang, "Electrochemical and DFT studies of $\beta$-amino-alcohols as corrosion inhibitors for brass", Electrochim. Acta, vol.52, pp.4554- 4559, 2007.

[30] M.A.Quraishi, D.Jamal, Dianils as new and effective corrosion inhibitors for mild steel in acidic solutions Mater. Chem. Phys. Vol.78, pp.608-613, 2003.

[31] G.M.Schmid \& H.J.Huang,Spectroelectrochemical studies of the inhibition effect 
of 4, 7-diphenyl -1, 10-phenanthroline on the corrosion of 304 stainless steel, CorrosSci, vol.20, pp.1041-1057, 1980.

[32] F.Bentiss, M.Lebrini \& M.Lagrenee, Thermodynamic characterization of metal dissolution and inhibitor adsorption processes in mild steel/2,5-bis(n-thienyl)-1,3,4thiadiazoles/hydrochloric acid system, CorrosSci, vol.47, pp.2915-2931, 2005.

[33] J.Marsh, Advanced Organic Chemistry, 3rd edn (Wieley Eastern, New Delhi), 1988.

[34] D.C.Silverman and J.E.Carrico, ,Electrochemical Impedance Technique - A Practical Tool for Corrosion Prediction Corrosion, vol.44, pp.280-187, 1988.

[35] W.J.Lorenz and F.Mansfeld, Determination of corrosion rates by electrochemical DC and AC methods, Corros.Sci. vol.21, pp.647-672, 1981.

[36] H.S.GADIYAR and N.S.D.ELAYATHU Corrosion and Magnetite Growth on Carbon Steels in Water at $310 \mathrm{C}$ - Effect of Dissolved Oxygen, pH, and EDTA Addition Corrosion, vol.36, pp.306-312, 1980.

[37 M.El-Achouri, S.Kertit, H.M.Gouttaya, B.Nciri , Y.Bensouda, L.Perez, Infante M.R., Elkacemi K., Prog. Org. Coat., vol.43, p.267, 2001
[38] J.R.Macdonald, W.B.Johanson in: J.R. Macdonald (Ed.), Theory in Impedance Spectroscopy, John Wiley\& Sons, New York, 1987.

[39] S.F.Mertens, C.Xhoffer , B.C.E.Decooman, Temmerman, Short-Term Deterioration of Polymer-Coated 55\% Al-Zn - Part 1: Behavior of Thin Polymer Films Corrosion, vol.53, pp.381- 388, 1997.

[40] G.Trabanelli, C.Montecelli, V.Grassi, A.Frignani, Electrochemical study on inhibitors of rebar corrosion in carbonated concrete, J. Cem. Concr., Res., vol.35, pp.1804-1813, 2005.

[41] A.J.Trowsdate, B.Noble, S.J.Haris, I.S.R.Gibbins., G.E.Thomson, G.C.Wood The influence of silicon carbide reinforcement on the pitting behaviour of aluminium,Corros. Sci., vol.38, pp.177-191, 1996 .

[42] F.M.Reis, H.G.De Melo and Costa Electrochemical Impedance Spectroscopy Selection of papers from the 6th International Symposium (EIS 2004) J., Electrochim.Acta, vol.51, pp.1375-1904, 2006. 